\title{
Temperature-dependent Development of Immature Carcinops pumilio (Coleoptera: Histeridae), a Predator of Musca domestica (Diptera: Muscidae) ${ }^{1,2}$
}

\author{
M. G. Fletcher, R. C. Axtell, R. E. Stinner and L. R. Wilhoit \\ Department of Entomology, North Carolina State University \\ Raleigh, NC 27695-7613
}

\begin{abstract}
J. Entomol. Sci. 26(1): 99-108 (January 1991)
ABSTRACT The development rates of the immature stages of Carcinops pumilio (Erichson), a predator on eggs and first instar larvae of the house fly, Musca domestica L. were determined at six constant temperatures: 17.5, 19.5, $25.5,30.0,32.5$ and $35.0^{\circ} \mathrm{C}$. At the six temperatures, respectively, the median development times (days) were for eggs: 25.5, 14.3, 7.4, 3.8, 3.5 and 3.5 ; for larvae $37.7,20.9,9.4,6.0,6.0$ and 6.0 ; and for pupae 42.8, 33.6, 17.0, 9.7, 7.4 and 8.3. Maximum development rates for all stages were at $32.5^{\circ} \mathrm{C}$. The percentage of survival at the six temperatures, respectively, for larvae were $66,92,98,100$, 93 and 93 , and for pupae were 56, 86, 90, 100, 93 and 78 . The parameters for the Sharpe and DeMichele (1977) temperature-dependent development model and the Stinner et al. (1975) distribution of development model were estimated from the constant temperature data and validated under a variable temperature cycle.
\end{abstract}

KEY WORDS Insecta, Carcinops pumilio, temperature, development, fly predator, house fly, models, Musca domestica.

House flies, Musca domestica L. (Diptera: Muscidae), are important pests in poultry production systems (Axtell 1985, Axtell and Arends 1990). Carcinops pumilio (Erichson) (Coleoptera: Histeridae), commonly found in poultry manure, is an important predator of house fly eggs and first instar larvae (Pfeiffer and Axtell 1980, Morgan et al. 1983, Geden 1984, Geden and Stoffolano 1987). The predation rates of this beetle have been determined and a model developed for the relationship between temperature and predation rates (Geden and Axtell 1988, Geden et al. 1988). Once the relationship between temperature and immature development has been determined, this information can be combined with the predation model to construct a simulation model to predict the impact of $C$. pumilio preation on house fly populations. The objective of this study was to estimate the parameters for the Sharpe and DeMichele (1977) temperature-dependent development model and the Stinner et al. (1975) distribution of development model.

\footnotetext{
1 Accepted for publication 24 October 1990.

2 The use of trade names in this publication does not imply endorsement by the North Carolina Agricultural Research Service nor criticism of similar ones not mentioned.
} 


\section{Materials and Methods}

Beetle eggs, larvae and pupae used in the experiments were $F_{1}$ progeny of adults collected in a poultry house in Duplin Co. North Carolina. The adults were maintained in a 1:1 mixture of poultry manure and house fly rearing medium, with water added to the mixture to obtain $60-65 \%$ moisture. Frozen house fly eggs were added daily to the colony at the rate of ca. 400 eggs per adult beetle.

Preliminary larval development tests were run at $15,20,25,30$, and $35^{\circ} \mathrm{C}$ with 12 larvae per temperature. These larvae were observed daily to obtain estimates of developmental time to pupation for each of the 5 temperatures; at $15^{\circ} \mathrm{C}$ there was no apparent development during a 90 day observation period. Based on these data, the $15^{\circ} \mathrm{C}$ incubator was adjusted to $17.5^{\circ} \mathrm{C}$ and a 6 th incubator was added at $32.5^{\circ} \mathrm{C}$. The actual temperature in each incubator was determined by a data logger (Campbell Scientific, Inc., Logan, Utah) set to record the temperature at 15 min. intervals. The mean temperature values of $17.5,19.5,25.5,30.0,32.5$ and $35.0^{\circ} \mathrm{C}$ were used in all parameter estimation calculations.

Egg development. The rates of development from egg deposition to hatch were determined using eggs oviposited within a $24 \mathrm{hr}$ period. The eggs were obtained by placing 100 adult beetles (1:1 sex ratio) with 800 frozen fly eggs per beetle into $150 \mathrm{cc}$ of the above medium (4 cm deep) in a screen-topped $200 \mathrm{ml}$ cup. Three cups (replicates) were placed in each of six incubators at temperatures of $17.5,19.5,25.5,30.0,32.5$ and $35.0^{\circ} \mathrm{C}\left( \pm 0.5^{\circ} \mathrm{C}\right)$, with a $16 \mathrm{~L}: 8 \mathrm{D}$ photoperiod. After $24 \mathrm{hr}$, the adult beetles were removed from the cups, leaving any beetle eggs that were oviposited. The cups were returned to the same incubators in which oviposition occurred. Subsequently, at $24 \mathrm{hr}$ intervals, the medium was examined under an illuminated magnifier and emerged larvae were counted and removed. In calculating egg development rates, it was assumed that all eggs were laid at the midpoint of the $24 \mathrm{hr}$ adult oviposition interval and emerged at the mid point between the $24 \mathrm{hr}$ observations. Examination of the medium took about $15 \mathrm{~min}$ per cup.

Larval development. For the larval development experiment, larvae were collected in the same manner as the eggs by placing 3,000 unsexed adults of $C$. pumilio along with 260 frozen fly eggs per beetle into 2,000 cc of medium for 24 hours in a 4 liter plastic container. When all adults subsequently were removed, the medium containing the beetle eggs was incubated at $27^{\circ} \mathrm{C}$. This single temperature was chosen so that exposure to all temperatures could be started on the same day and run simultaneously with larvae of the same age and stage of development. After 4.5 days, the medium was examined and newly hatched larvae discarded, the medium then divided into six equal amounts and placed into 1-liter plastic containers. One container was placed at each of the six temperatures for 24 hr, after which 48 newly hatched larvae were removed from each container and divided into four replicates of 12 each and returned to the same temperature. Each larva was held individually in a $30 \mathrm{cc}$ plastic cup containing $15 \mathrm{cc}$ of rearing medium described above. To minimize desiccation, each cup was placed in a 200 cc covered plastic container lined with moist tissue paper. Three days before the estimated time of pupation (based on the preliminary experiment described above), the cups were examined at $24 \mathrm{hr}$ intervals under an illuminated magnifier to detect the presence of pupae. Two of the 12 cups per replicate were examined each day until $50 \%$ of those observed had pupated, after which all cups were 
examined. The cups were examined in rotation so that an individual larva was disturbed only once before the final examination.

During the course of this experiment, each larva received 8000 frozen house fly eggs and 200 live fruit fly larvae, Drosophila repleta Wollaston. Due to high mortality of the fruit fly larvae at 32.5 and $35.0^{\circ} \mathrm{C}$, ca. 50 live larvae were added daily to each cup held at those temperatures until the beetle larvae pupated. Live fruit fly larvae were added every other week to the cups held at 17.5 an $19.5^{\circ} \mathrm{C}$ because at these lower temperatures the fruit fly larvae pupated before the $C$. pumilio larvae. Extra fruit fly larvae were added to the containers held at the highest and lowest temperatures to maintain the number of larvae available as prey equal to that at the middle temperatures.

Since beetle larvae held at 32.5 and $35.0^{\circ} \mathrm{C}$ pupated in a short time (six days), all the cups were examined the day before pupation was expected. This examination disrupted normal pupal cell construction because most of the larvae would not then construct pupal cases for at least another 48 hours. To obtain a more accurate estimate of larval development rate at these two temperatures, three additional replicates (10 larvae each) were used. The $30 \mathrm{cc}$ cups were placed into a $35 \times 26.5 \times 9 \mathrm{~cm}$ plastic box lined with moist paper towel to raise the humidity and prevent drying of the media. A single observation was made on the day pupation was expected, based on the previous experiments.

Pupal development. The development rate from pupation to adult emergence was determined by observing the same indivdiuals used in the larval development experiments. The development rates for 32.5 and $35^{\circ} \mathrm{C}$ were determined from the second group of larvae described above. All cups were observed daily by examining the media under an illuminated magnifier.

The mean proportion survival was calculated for the larvae and pupae by dividing the number completing that life stage by the number of immatures per replicate at the beginning of the life stage (12 or 10 for the larvae; the number varied for the pupae since not all larvae pupated).

Data analysis. The data were fit to the Sharpe and DeMichele (1977) poikilotherm model with high temperature inhibition. This model has the form:

$$
\mathrm{r}(\mathrm{K})=\frac{\mathrm{RH} 025 \times \frac{\mathrm{K}}{298.15} \times \exp \left[\frac{\mathrm{HA}}{1.987}\left(\frac{1}{298.15}-\frac{1}{\mathrm{~K}}\right)\right]}{1+\exp \left[\frac{\mathrm{HH}}{1.987}\left(\frac{1}{\mathrm{TH}}-\frac{1}{\mathrm{~K}}\right)\right]} \text { (Eq. 1) }
$$

where $\mathrm{r}(\mathrm{K})=$ median rate of development $\left(\right.$ days $\left.^{-1}\right)$ at temperature $\mathrm{K}\left({ }^{\circ} \mathrm{Kelvin}={ }^{\circ} \mathrm{C}\right.$ + 273.15). RH025, HA, TH and $\mathrm{HH}$ are parameters estimated by the nonlinear regression routine outlined by Wagner et al. (1984) using NLIN procedure (SAS Institute 1985). RH025 is the development rate at $25^{\circ} \mathrm{C}\left(298.15^{\circ} \mathrm{K}\right)$ assuming no inactivation of the rate controlling enzyme, $\mathrm{HA}$ is the enthalpy (sum of energies in the system) of activation of a hypothetical reaction that is catalyzed by a ratecontrolling enzyme, TH is the temperature $\left({ }^{\circ} \mathrm{K}\right)$ at which the enzyme is half inactivated by high-temperature inhibition, and $\mathrm{HH}$ is the change in enthalpy associated with the high-temperature inactivation. For a discussion of the biological 
significance of these parameters, see Wagner et al. (1984) and Schoolfield et al. (1981). Hourly temperature data were used to calculate the parameters for each stage and for the entire immature development. The goodness of fit or accuracy of the model was determined by linear regression of the observed versus the predicted development rates using the REG procedure (SAS Institute 1985). If the predicted values are accurate estimates of the observed values there should be a linear relationship between them with a high $\mathrm{R}^{2}$ and the slope of the regression should not be significantly different from 1 and the intercept should not be significantly different from $\mathrm{O}$.

The predicted median development rate was calculated by the Sharpe and DeMichele equation. The variation, or distribution, of development about that median rate for the combined immature stages (oviposition to adult emergence) at the different temperatures was modeled using the approach of Stinner et al. (1975). When the cumulative distribution of development is predicted as a function of chronological age, each temperature has its own unique distribution and thus one can not predict the distribution under a variable temperature cycle. When expressed as a function of median physiological age (time of cumulative proportion of development divided by median time for development), all temperatures produce the same developmental distribution and may be expressed by one equation which has the form:

$$
\mathrm{Y}=(1-\mathrm{z})^{\mathrm{Kz}^{2}}
$$

where $z=(B-p) /(B-A), A$ is the physiological age of those to emerge first, $B$ is the physiological age of those to emerge last and $\mathrm{K}$ is calculated directly from $\mathrm{A}$ and B (Stinner et al. 1975). The goodness of fit was determined by linear regression of observed versus predicted development times using the REG procedure (SAS Institute 1985).

Model validation. The temperature-dependent development (Eq. 1) and distribution (Eq. 2) models were validated under variable temperature conditions using the following procedure. About 600 unsexed beetle adults per replicate were placed into $500 \mathrm{cc}$ of medium and 250 frozen house fly eggs added per beetle. Each of four replicates was in a 1-liter translucent plastic container, insulated around the outside with wood shavings, and placed $1 \mathrm{~m}$ above the ground in an open-sided poultry house. They were elevated to prevent rodents and other insects from disturbing the containers. After $24 \mathrm{hr}$, the adults were removed by sorting the medium and the medium containing the oviposited beetle eggs was returned to the poultry house. Two hundred cc of fruit fly medium heavily infested with 1-2 day old beetle larvae and about 8000 frozen house fly eggs were added to the container 3 days after removal of the adults. Fifty cc of the fruit fly medium was added 11 and 14 days after adult removal. The immature $C$. pumilio were examined every other day until the first adults emerged. The medium was then examined daily, and the adults counted and removed.

Three of the 4 containers in the validation study had a temperature probe in the center of the media, $2 \mathrm{~cm}$ deep and connected to a data logger (Campbell Scientific, Inc., Logan, Utah), to record hourly temperatures. The average hourly temperatures for the three containers were used to run a simulation of $C$. pumilio development using the parameters from the Sharpe and DeMichele equation for 
total immature development (i.e., from oviposition to adult emergence). The predicted and observed distributions of adult emergence were then compared.

\section{Results and Discussion}

The longest development times for eggs, larvae and pupae were observed at $17.5^{\circ} \mathrm{C}$ with development times decreasing as temperature increased (Table 1). At all six temperatures, the egg stage had the shortest development times, with the larval and pupal stages at each temperature requiring a progressively longer period to develop. Morgan et al. (1983) reported mean development times at $25^{\circ} \mathrm{C}$ for eggs, larvae and pupae of $6.3,15.5$ and 17.5 days, respectively, compared to our values at $25.5^{\circ} \mathrm{C}$ of $6.6,9.9$ and 17.6 days, respectively. Geden (1984) reported development times at 30 to $31^{\circ} \mathrm{C}$ for eggs, larvae and pupae of $3.0,9.3$, and 9.3 days, respectively. Geden divided the pupal period into two separate phases: cell construction to pupation (2.9 days) and pupation (6.4 days). Our mean development times at $30^{\circ} \mathrm{C}$ were $3.8,6.0$ and 10.3 days for egg, larvae and pupae, respectively, using construction of pupal case as the end of larval development and beginning of pupation. The longer larval development times reported by Morgan et al. (1983) and Geden (1984) were based on experiments involving larval disturbance during the observations, which probably delayed the construction of the pupal case. However, the total development time (egg-adult) reported by Geden (21.6 days) was similar to our data (20.1 days). Observations from the present experiment suggest that if a larva is disturbed during construction of its pupal case, the larva will not attempt to build another for 24 to 48 hours. Eggs and pupae did not seem to be affected by disturbances.

Maximum survival was $100 \%$ and observed at $30^{\circ} \mathrm{C}$ for both larvae and pupae, minimum survival was $66 \%$ and $56 \%$ observed at 17.5 for larvae and pupae respectively (Table 2). Survival was generally higher and less affected by temperature for larvae as compared with pupae. Larval survival ranged from $66 \%$ at $17.5^{\circ} \mathrm{C}$ to $100 \%$ at $30^{\circ} \mathrm{C}$ with a reduction to $93 \%$ at $35^{\circ} \mathrm{C}$. Pupal survival at those same temperatures ranged from $56 \%$ to $100 \%$ to $78 \%$. Survival estimates were not made for eggs because the number oviposited in the media was unknown.

The parameter estimates for the Sharpe and DeMichele model (Eq. 1) are presented in Table 3. The predicted development times for eggs, larvae, pupae and combined immature stages at each of the six temperatures were not significantly different from the observed values as determined by linear regression $(P=0.05)$ (Table 1). Parameter estimates for the pupal stage included an additional interpolated data point at $33.5^{\circ} \mathrm{C}$ in order to obtain convergence of the nonlinear regression (for explanation see pp. 583-584, SAS User's Guide: Statistics, 1985).

For the combined immature development (egg to adult), the cumulative proportion of adult emergence for each temperature, when based on chronological age has its own unique starting time and distribution (Figure 1). by transforming chronological age to median physiological age, the cumulative proportion of emergence for each temperature can be described by a single equation (Eq. 2) with similar starting points and distributions (Figure 2). The parameter estimates for Equation 2 are $\mathrm{A}=0.904, \mathrm{~B}=1.13$ and $\mathrm{K}=2.4467$. For the complete immature development over a temperature range of $17-35^{\circ} \mathrm{C}$, the range was 0.86 to 0.95 for A and 1.02 to 1.28 for B. 
Table 1. Mean $( \pm \mathrm{SD})$ and median (observed and predicted) number of days for egg, larval, pupal, and total immature development of Carcinops pumilio at six constant temperatures.

\begin{tabular}{|c|c|c|c|c|c|}
\hline \multirow[b]{2}{*}{ Stage } & \multirow[b]{2}{*}{${ }^{\circ} \mathrm{C}$} & \multirow[b]{2}{*}{ Mean $( \pm S D)$} & \multicolumn{2}{|c|}{ Median } & \multirow[b]{2}{*}{$\mathrm{R}^{2 *}$} \\
\hline & & & Obs. & Pred. & \\
\hline \multirow[t]{6}{*}{ Egg } & 17.5 & $24.0(1.3)$ & 25.5 & 22.6 & 0.996 \\
\hline & 19.5 & $14.5(1.4)$ & 14.3 & 15.9 & \\
\hline & 25.5 & $6.6(1.1)$ & 7.4 & 6.6 & \\
\hline & 30.0 & $3.8(0.6)$ & 3.8 & 3.4 & \\
\hline & 32.5 & $3.1(0.3)$ & 3.5 & 2.9 & \\
\hline & 35.0 & $2.9(0.1)$ & 3.5 & 3.0 & \\
\hline \multirow[t]{6}{*}{ Larva } & 17.5 & $37.7(4.1)$ & 37.7 & 36.3 & 0.999 \\
\hline & 19.5 & $21.6(1.1)$ & 20.9 & 21.8 & \\
\hline & 25.5 & $9.9(1.1)$ & 9.4 & 9.3 & \\
\hline & 30.0 & $6.0(0.1)$ & 6.0 & 6.1 & \\
\hline & 32.5 & $5.9(0.4)$ & 6.0 & 5.9 & \\
\hline & 35.0 & $6.1(0.3)$ & 6.0 & 6.1 & \\
\hline \multirow[t]{6}{*}{ Pupa } & 17.5 & $43.6(3.9)$ & 42.8 & 43.7 & 0.998 \\
\hline & 19.5 & $34.1(2.3)$ & 33.6 & 32.3 & \\
\hline & 25.5 & $17.6(1.1)$ & 17.0 & 17.5 & \\
\hline & 30.0 & $10.3(0.9)$ & 9.7 & 9.5 & \\
\hline & 32.5 & $7.9(1.0)$ & 7.4 & 7.5 & \\
\hline & 35.0 & $8.6(0.7)$ & 8.3 & 8.3 & \\
\hline Immature & 17.5 & $105.3 \dagger$ & 105.5 & 101.0 & 0.990 \\
\hline \multirow[t]{5}{*}{ (Total) } & 19.5 & 70.2 & 69.0 & 71.3 & \\
\hline & 25.5 & 34.1 & 35.2 & 35.6 & \\
\hline & 30.0 & 20.1 & 19.5 & 19.2 & \\
\hline & 32.5 & 16.9 & 16.7 & 16.9 & \\
\hline & 35.0 & 17.6 & 18.1 & 18.1 & \\
\hline
\end{tabular}

* $\mathrm{R}^{2}$ is the square of the Pearson product-moment correlation coefficient. $\mathrm{R}^{2}$ of predicted versus observed median number of days to completion of development. In all cases the slope and intercept were not significantly different from 1 and 0 , respectively $(\mathrm{P}=0.05)$.

$\uparrow$ Sum of the mean development times for each stage at that temperature.

Table 2. Mean ( \pm SD) proportion survival for larvae and pupae of Carcinops pumilio at six constant temperatures.

\begin{tabular}{cccccc}
\hline \hline & \multicolumn{2}{c}{ Larvae } & & \multicolumn{2}{c}{ Pupae } \\
\cline { 2 - 3 } Temperature & $\mathrm{n}$ & & & $\mathrm{n}$ & $\%$ \\
\hline 17.5 & 48 & $0.66(0.15)$ & & 32 & $0.56(0.26)$ \\
19.5 & 48 & $0.92(0.06)$ & & 44 & $0.86(0.22)$ \\
25.5 & 48 & $0.98(0.04)$ & & 47 & $0.90(0.12)$ \\
30.0 & 48 & $1.00(0.00)$ & & 48 & $1.00(0.00)$ \\
32.5 & 30 & $0.93(0.12)$ & & 28 & $0.93(0.07)$ \\
35.0 & 30 & $0.93(0.06)$ & & 28 & $0.78(0.20)$ \\
\hline
\end{tabular}

$\mathrm{n}=$ Number starting each life stage. 
Table 3. Parameter estimates for the Sharpe and DeMichele (1977) model of temperature-dependent median rate of development of the eggs, larvae and pupae of Carcinops pumilio.

\begin{tabular}{lcccr}
\hline \hline Stage & RH025 & HA & TH & HH \\
\hline Eggs & 0.160117 & 29615.7 & 307.0 & 64539.0 \\
Larvae & 0.162329 & 38001.0 & 300.7 & 48717.5 \\
Pupae & 0.058122 & 20333.5 & 308.5 & 208431.6 \\
Immature & 0.028944 & 23472.6 & 308.1 & 84996.8 \\
(Total) & & & & \\
\hline
\end{tabular}

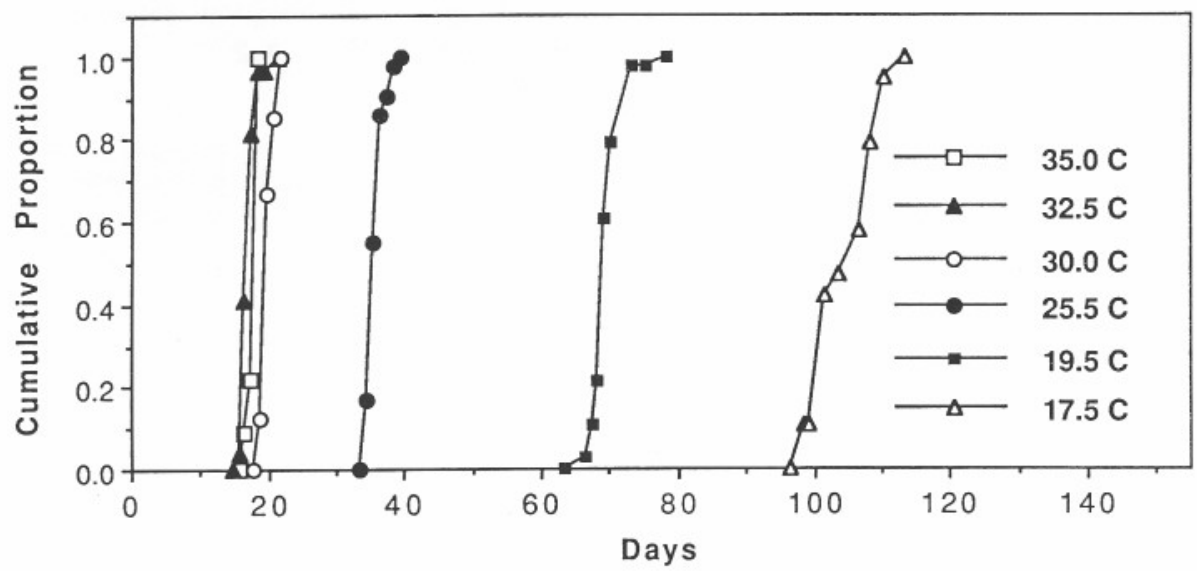

Fig. 1. Cumulative proportion of adult emergence of C. pumilio held in medium at six constant temperatures from egg to adult: $\mathrm{x}$ axis is chronological age.

During the validation study 379 adults emerged, with all emergences between days 26 and 31 (Figure 3). The results of the validation for the total immature temperature-dependent development model using hourly temperature data indicated that the predicted time of median adult emergence (29.7 days, Eq. 1) was outside the observed values ( 26.0 to 29.5 days). The average temperature during the validation experiment was $26.4^{\circ} \mathrm{C}$, range 16 to $44^{\circ} \mathrm{C}$. Temperatures above $32^{\circ} \mathrm{C}$ were observed to be lethal to the fruit fly larvae, though there was substantial adult fruit fly emergence. This suggests that the fruit fly larvae were able to migrate to areas of more favorable temperatures within the medium. the C. pumilio larvae also probably moved to areas of lower temperature. Therefore, the model was rerun placing an arbitrarily set maximum temperature of $35^{\circ} \mathrm{C}$ on the hourly temperature data file. With this limit on the maximum temperature, the model predicted a median emergence time (28.7 days) within the range of the observed values (Fig. 3). The necessity for these adjustments also demonstrates the importance of accurate microhabitat temperature estimation in modeling. 


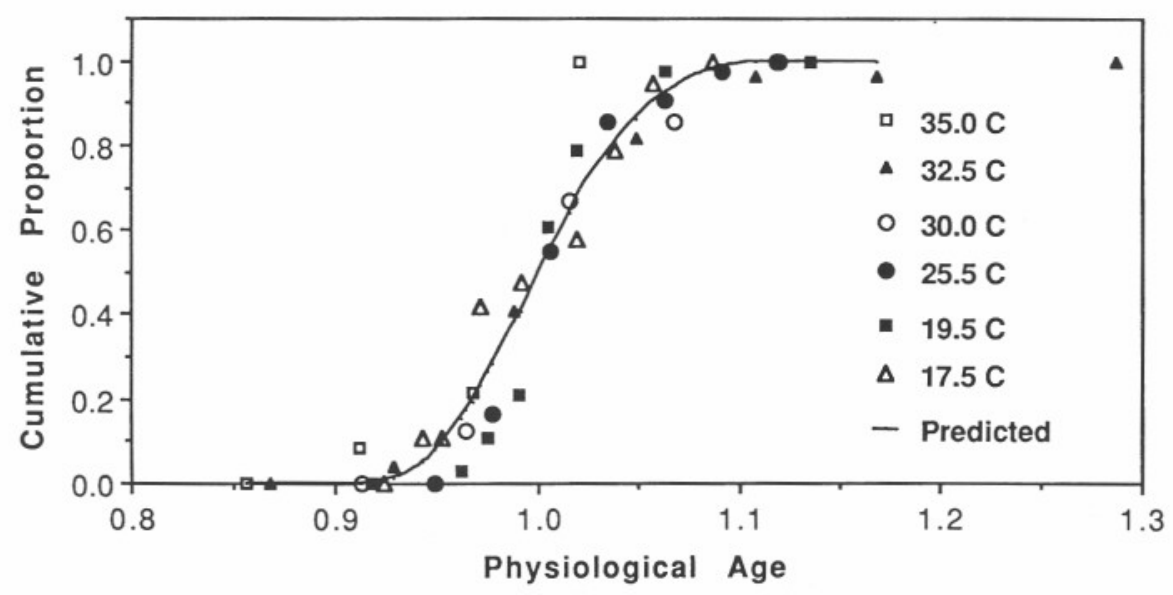

Fig. 2. Cumulative proportion of adult emergence of C. pumilio at six constant temperatures compared to predicted distribution based on median physiological age (1.0 physiological age equals 0.5 cumulative proportion.)

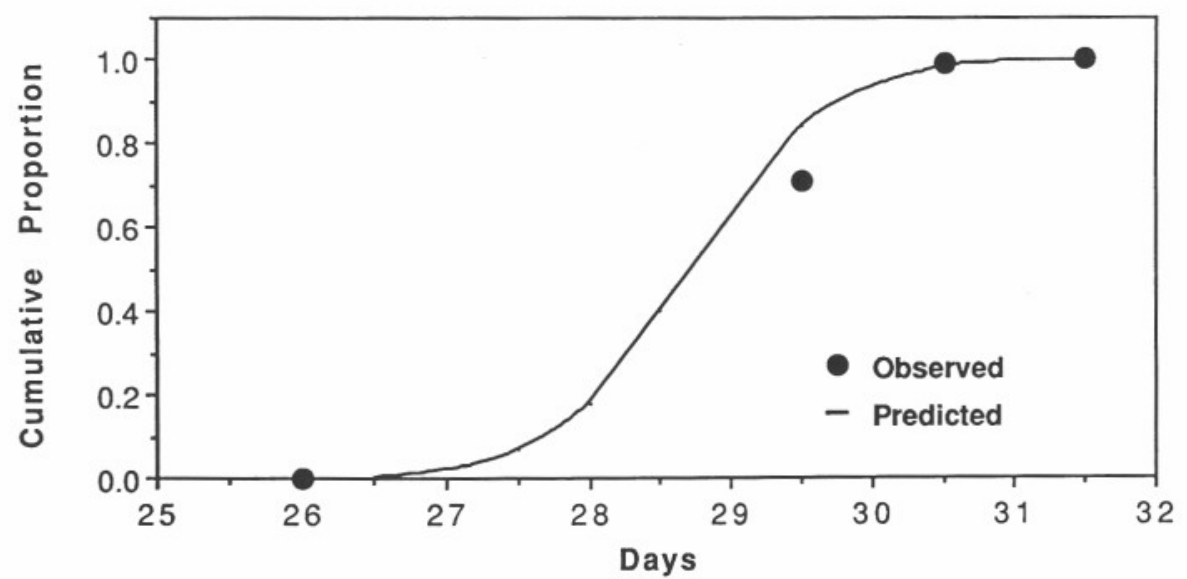

Fig. 3. Results of the validation (observed versus predicted) for the model of immature development (oviposition to adult emergence) of $C$. pumilio using hourly temperatures. 
The cumulative predicted distribution of emergence (Eq. 2) was not significantly different from the observed distribution as determined by linear regression $\left(\mathrm{R}^{2}=0.97\right.$; slope and intercept were not significantly different from 1 and 0 , respectively, $\mathrm{P}=0.05$ ). Thus, the combined models (Eq. $1 \& 2$ ) were able to accurately predict the time distribution of adult emergence based on hourly temperatures.

These models of the temperature-dependent development rate of immature $C$. pumilio have been combined with models for predation rates (Geden and Axtell 1988 ) in the development of a simulation model of $C$. pumilio impact on house fly population dynamics (Axtell and Stinner 1990). An overall fly management model, incorporating this C. pumilio model and similar models for other predators and parasites, is being developed. The fly management model will facilitate comparing the effects of various control strategies and lead to a better understanding of the relationship between the house fly and its predators and parasites.

\section{Acknowledgments}

The research in this publication was funded in part by the North Carolina Agriculture Research Service and USDA-Cooperative States Research Service Agreements No. 86CSRS-2889 and 89-341-3-4240. The authors thank T. D. Edwards for assistance.

\section{References Cited}

Axtell, R. C. and R. E. Stinner. 1990. Computer simulation modeling of fly management, pp. 265-291. In: D. A. Rutz and R. S. Patterson (eds.), Biocontrol of arthropods affecting livestock and poultry. Westview Press, Boulder, Colorado.

Axtell, R. C. 1985. Fly management in poultry production: Cultural, biological and chemical. Poultry Sci. 65: 657-667.

Axtell, R. C. and J. J. Arends. 1990. Ecology and management of arthropod pests of poultry. Annu. Rev. Entomol. 35: 101-126.

Geden, C. J. 1984. Population dynamics, spatial distribution, dispersal behavior and life history of the predaceous histerid, Carcinops pumilio (Erichson), with observations of other members of the poultry manure arthropod community. Ph.D. dissertation, Univ. of Massachusetts, Amherst. 220 p.

Geden, C. J. \& J. G. Stoffolano, Jr. 1987. Succession of manure arthropods at a poultry farm in Massachusetts, USA, with observations on Carcinops pumilio (Coleoptera: Histeridae) sex ratios, ovarian condition and body size. J.Med. Entomol. 24: 212-220.

Geden, C. J. and R. C. Axtell. 1988. Predation by Carcinops pumilio (Coleoptera: Histeridae) and Macrocheles muscaedomesticae (Acarina: Macrochelidae) on the house fly (Diptera: Muscidae): Functional response, effects of temperature, and availability of alternative prey. Environ. Entomol. 17: 739-744.

Geden, C. J., R. E. Stinner, and R. C. Axtell. 1988. Predation by predators of the house fly in poultry manure: Effects of predator density, feeding history, interspecific interference, and field conditions. Environ. Entomol. 17: 320-329.

Morgan, P. B., R. S. Patterson, and D. E. Weidhaas. 1983. A life history study of Carcinops pumilio Erichson (Coleoptera: Histeridae). J. Ga. Entomol. Soc. 18: 353-359.

Pfeiffer, D. G. and R. C. Axtell. 1980. Coleoptera of poultry manure in caged layer houses in North Carolina. Environ. Entomol. 9: 21-28.

SAS Institute. 1985. SAS user's guide: statistics. SAS Institute, Cary, NC.

Schoolfield, R. M., P. J. H. Sharpe, and C. E. Magnuson. 1981. Nonlinear regression of biological temperature-dependent rate models based on absolute reaction-rate theory. $\mathrm{J}$. Theor. Biol. 88: 719-731. 
Sharpe, P. J. H. and D. W. DeMichele. 1977. Reaction kinetics of poikilotherm development. J. Theor. Biol. 64: 649-670.

Stinner, R. E., G. D. Butler, Jr., J. S. Bacheler, and C. Tuttle. 1975. Simulation of temperature-dependent development in population dynamics models. Can. Entomol. 107: 1167-1174.

Wagner, T. L., H. I. Wu, P. J. H. Sharpe, R. M. Schoolfield, and R. N. Coulson. 1984. Modeling insect development rates: A literature review and application of a biophysical model. Ann. Entomol. Soc. Am. 77: 208-225. 